\title{
Using Flipped Classroom Model: Factors Influencing Students' Satisfaction
}

\author{
Kamaludeen Samaila $^{1 \star}$ (), Mona Masood ${ }^{2}$ (), Kien Tsong Chau ${ }^{2}$ ()
}

${ }^{1}$ Kebbi State University of Science and Technology, Aliero, NIGERIA

${ }^{2}$ Centre for Instructional Technology and Multimedia, Universiti Sains Malaysia, Pulau Pinang, MALAYSIA

*Corresponding Author: elkamaljega@gmail.com

Citation: Samaila, K, Masood, M., \& Chau, K. T. (2021). Using Flipped Classroom Model: Factors Influencing Students' Satisfaction. European Journal of Interactive Multimedia and Education, 2(2), e02112. https://doi.org/10.30935/ejimed/11260

\begin{abstract}
The traditional lecture-based method has been used in universities, colleges, and schools to assimilate the knowledge. A modern method of teaching is needed to overcome the limitations and challenges of the traditional lecture-based method, to improve students' satisfaction and to increase learning outcomes. Among the modern methods of teaching, a flipped classroom (FC) model has recently been implemented as an alternative method of teaching. To explore students' satisfaction in a flipped classroom model, a quantitative approach with a questionnaire as an instrument was used for data collection from an accessible sample size of 110 students. The results from a Partial Least Square Structural Equation Modelling (PLS-SEM) indicated that perceived value has positively influenced students' satisfaction. However, the results further revealed that instructor-generated video content, perceived usefulness, and perceived ease of use were found to have no positive influence on students' satisfaction. The study makes some recommendations that aid in the design and implementation of the FC model. It also offers additional information for those who wish to adopt the FC model in their institutions.

Keywords: flipped classroom model, flipped learning, instructor-generated video content, perceived usefulness, perceived ease of use, perceived value, higher education

Received: 15 Jun. $2021 \bullet$ Accepted: 17 Aug. 2021
\end{abstract}

\section{INTRODUCTION}

Contemporary learning approaches in higher institutions such as elearning, blended learning, and flipped classroom have been continually advancing by the increased availability of the Internet, video technology, and computer-based learning. Among the new methods, flipped classroom model has emerged as one of the influential models (Lai \& Hwang, 2016); improving students' learning outcomes (Wen, Zaid, \& Harun, 2017). Flipped classroom (FC) model is a pedagogy in which the lecture materials are being given to the students before class time while classroom time is used for discussion, problem-solving, assessment, individual learning, and presentation (O'Flaherty \& Phillips, 2015). In the FC model the role of the teacher includes preparing recorded lecture materials, guiding, facilitation, supporting, giving feedback, and evaluating the learning process (Lizhu et al., 2018) and provide a conducive environment for individualized learning (Lai, 2015). The student's role in FC model is to watch pre-recorded video content, complete learning activities and participate actively in the online discussion before the class hour. During classroom time the students should be active constructors of knowledge (Bergmann \& Sams, 2012; Elian \& Hamaidi, 2018).

The objective of the FC model is to overcome the challenges and limitations of traditional teaching methods by ensuring students learn at their own pace and making learning interactive, flexible, and collaborative (Yilmaz, 2017). The model allows students to review recorded lectures repeatedly (Heijstra \& Sigurðardóttir, 2018), supports student-centered learning (Kim et al., 2014), encourages active learning, and offers adequate time for students to collaborate and work with peers in the classroom (Ozdamli \& Asiksoy, 2016; Toto \& Nguyen, 2009).

There are studies reported multiple advantages of FC model, some studies disclosed the limitations and challenges of the FC model. For example, FC model requires a monetary investment and time to develop flipped classroom courses (Wu, Hsieh, \& Yang, 2017). FC model could not be suitable for students with low self-directed learning skills and poor self-regulated learning behavior (Lai \& Hwang, 2016), inability of the students to complete their pre-class learning activities ahead of the class (Lo, Lie, \& Hew, 2018; Manoj, Renumol, \& Murthy, 2019; Zainuddin et al., 2019). These issues raise a serious concern over the students' satisfaction in the FC model (Bishop \& Verleger, 2013; Zhai et al., 2017). The problem of inadequate literature on the relationship between technological and social factors with students' satisfaction in the FC model has not been well explored (Zhai et al., 2017). Therefore, this study covers the existing gap by exploring students' satisfaction in the FC model. 


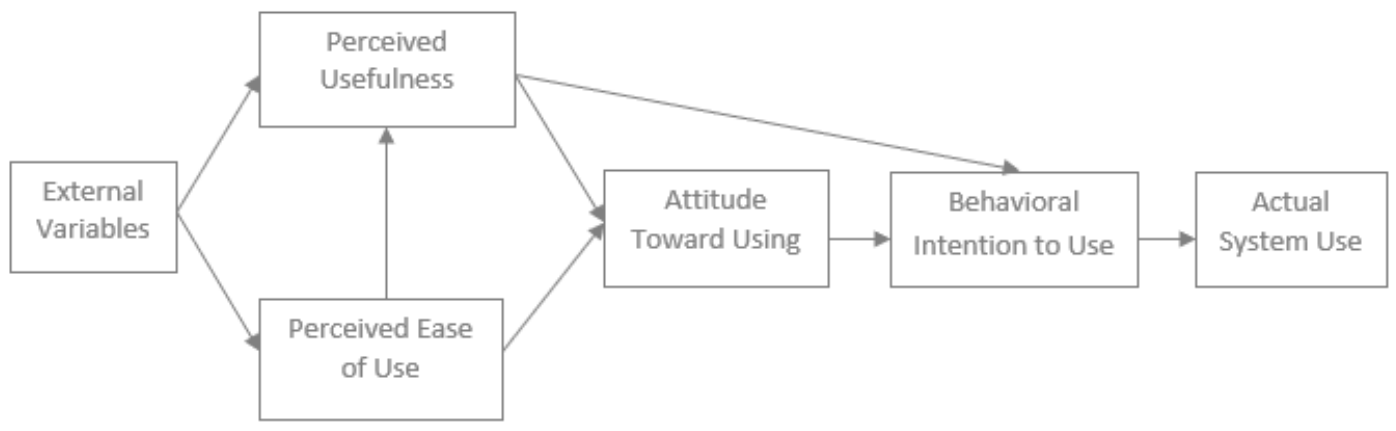

Figure 1. Technology Acceptance Model (TAM)

This study investigates the influence of perceived usefulness and perceived ease of use, perceived value, on students' satisfaction. In achieving this, Perceived usefulness was adopted from the technology acceptance model (TAM). It reflects the extent to which students believed that using FC strategy enhanced their academic achievements (Zhai et al., 2017). Perceived ease of use was adopted from TAM, of which it refers to as the degree to which students are convinced that the FC model is easy and effortless to adopt (Zhai et al., 2017). Perceived value is the students' evaluation of the importance of an FC model and its ability to meet the needs and expectations, particularly when compared with traditional methods (Al-Debei \& Al-Lozi, 2014). Instructor-generated video contents are learning materials prepared by the instructor in video format for students to study while at home.

This research examines four research questions as stated below:

1. What is the influence of instructor-generated video content on student's satisfaction in flipped classroom model?

2. What is the influence of perceived usefulness on student's satisfaction in flipped classroom model?

3. What is the influence of perceived ease of use on student's satisfaction in flipped classroom model?

4. What is the influence of perceived value on student's satisfaction in flipped classroom model?

The answer to these questions is important because it helps in the design, implementation, and assessment of the FC model. The answer could also be used to explain what factor is the most needed for students' satisfaction particularly in FC model.

\section{THEORETICAL BACKGROUND}

The theoretical background gives an overview of the theories used in the study. It comprises the models that form the foundation, and justifications for the research questions and hypotheses.

\section{Technology Acceptance Model (TAM)}

The model argues that when students are presented with an innovation, several elements influence their decisions about when and how they will use it. TAM (1989) is a well-known information technology theory for evaluating individual's acceptance of technology and use of emerging technologies (Portz et al., 2019) and has been widely utilized to investigate students' satisfaction in the multimedia learning environment (Al-hawari \& Mouakket, 2010). The TAM proposes that perceived usefulness and perceived ease are the main elements used in determining students' attitude, while attitude is the main factor for determining behavioral intention and behavioral intention influences usage (see Figure 1).

This model has been modified to fit different studies. The modification of the model was mostly the removal or addition of constructs and in some cases the addition of mediators or moderators. However, the model has limitations identified in the previous studies such as TAM's inability of recognizing other issues. For instance, structural imperatives and cost that push students to adopt and utilize an innovation. Despite the limitations, many studies (Rahman et al., 2015; Zhai et al., 2017) used the TAM to examine students' satisfaction when implementing new instructional technologies. Because of the TAM's simplicity and implication, this study adopts it to achieve the stated objectives.

\section{Flipped Classroom (FC) Model}

FC model is a modern method of teaching and learning in which the lectures are being delivered ahead of class time via asynchronous online video content and employs a group-based learning approach in the classroom (Bishop \& Verleger, 2013). This method has been recommended as the effective modern pedagogy that develops learning experience for both instructors and learners in the twenty-first century (Lai, 2015). It is rapidly adopted and implemented in different categories of education (Missildine et al., 2013). Research suggested that the FC model is flexible and offers different learning styles, allows teachers to create a learning space in which the students can select where, when, and how to learn (Ahuja, 2020). Previously, flipped learning network study reported that students were better-off with flipped classroom mode than the traditional lecture-based method (Sams et al., 2014). Another study revealed that the FC model increased teacher-student interaction and improved class attendance and student mastery (Cheng et al., 2017). Although previous studies explained that students had a positive perception and attitude toward flipped classrooms than traditional instruction (Onojah et al., 2019), the literature for students' satisfaction in FC model is scant. Most of the studies focused on the effectiveness and efficacy of the FC model with less effort on investigating the cause of students' satisfaction in FC model.

\section{Studen ts' Satisfaction and FC Model}

Satisfaction is the extent to which an individual satisfies that a specific service is reliable (Ong, Day, \& Hsu, 2009). Satisfaction plays a significant role in deciding whether the user continues to use the system or not (Tarafdar, Tu, \& Ragu-Nathan, 2010). Users' satisfaction with the FC approach is an important measure that reflects the success of this approach in serving students. The factors affecting users' satisfaction 


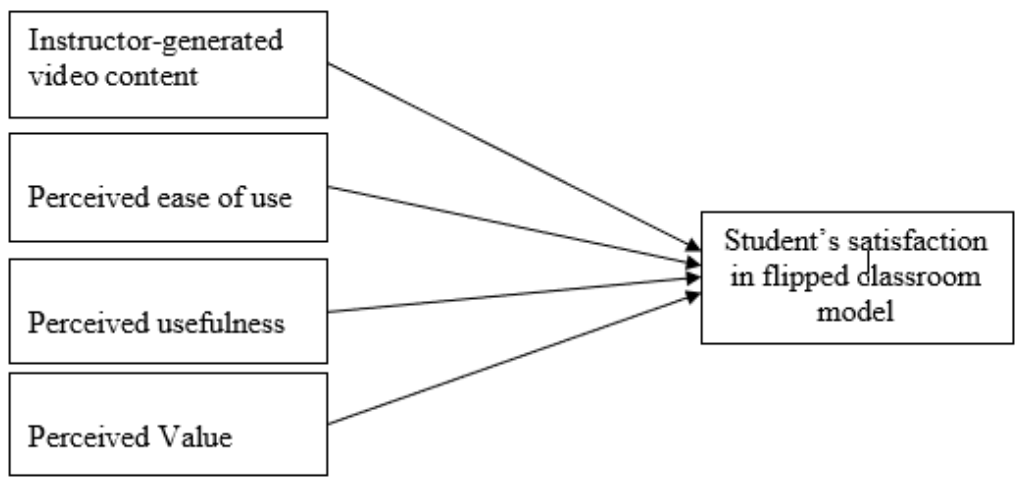

Figure 2. Conceptual model of the study

had long been explored in the field of blended learning and e-learning (Chen \& Tat Yao, 2016; Hammouri \& Abu-Shanab, 2018; Ibrahim et al., 2019; Mtebe \& Raphael, 2018; Nortvig, Petersen, \& Balle, 2018). These studies argued that students' satisfaction would increase system usage, improve system acceptance and adoption. Therefore, the study of students' satisfaction may provide more insights concerning flipped learning strategies.

\section{FACTORS AND STUDENTS' SATISFACTION IN FC CONTEXT}

There is a need to explore the best factors relating to the student's satisfaction in the FC model. The factors selected for investigation are instructor-generated video content, perceived usefulness, perceived ease of use, and perceived value.

Figure 2 is a conceptual model of the research which shows the direct relationship between independent variables and dependent variable.

\section{Instructor-Generated Video Content and Students' Satisfaction}

Most of the studies (Murillo-Zamorano, López Sánchez, \& GodoyCaballero, 2019; Yilmaz, 2017; Zhai et al., 2017) evaluate the relationship between factors (such as e-learning readiness, perceived quality, perceived value, knowledge, and skills) and students' satisfaction. Little or no research investigates the influence of instructor-generated video content on students' satisfaction in the FC environment. Instructor-generated video lectures are lecture materials that the teacher or instructor prepares in a video format for students to watch and learn before the class hour. The video helps the students to acquire basic knowledge and engages them during pre-class learning activities (D'Aquila, Wang, \& Mattia, 2019). Nevertheless, many teachers believed that third-party recorded video lectures adopted either from YouTube, Vimeo, or Khan Academy are also sources of learning content for the FC (Panopto, 2015).

A study investigated the effect of instructor-generated video content on students' satisfaction. Results showed that students were more satisfied with instructor-generated video content than the thirdparty video content (Draus et al., 2014). The results further revealed instructor-generated video content was among the critical elements that had significantly influenced students' satisfaction in online courses. Another study was carried out to assess the influence of instructorgenerated video on students' satisfaction in an undergraduate Accountancy course. The findings showed that instructor-generated video techniques had a strong significant influenced on students satisfaction (Yusuf \& Prasad, 2017). To address the issue of lack of social presence in online teaching and learning; Miller and Redman (2010) used self-recorded videos to teach online astronomy courses in a University. Results showed that self-recorded videos had proven to increase students' satisfaction, performance, and perception. There is a research reported that instructor-generated video content motivates and engages the students to watch video content during pre-class activities (Panopto, 2015) more than the unverified third-party video content in online learning. This makes the use of instructor-generated video content within online education a vital factor to study (Revere \& Kovach, 2011; Robinson \& Stubberud, 2012). Based on the literature, the researchers formulated the following hypothesis:

Hypothesis 1: Instructor-generated video has positively influenced students' satisfaction.

\section{Perceived Usefulness and Students' Satisfaction}

Perceived usefulness (PU) is one of the key constructs of the technology acceptance model (TAM) and has been regarded as the crucial factor for predicting students' satisfaction in an online and blended learning environment. It is defined as the extent to which an individual believes that technology will improve his or her job performance and satisfaction (Davis, 1989). According to Hammouri and Abu-Shanab (2018), perceived usefulness can be described as the degree to which students agreed that using an e-learning system would give them chances to learn at their own pace, enhance their performance and save more time. In the flipped classroom context, PU is the extent to which students believes that using online video and interactive platform will improve their academic performance (Zhai et al., 2017). PU is the extent student believes flipped learning pedagogy helps him or her to achieve learning goals and desires. To fully assess the efficacy of the FC model, researchers have begun to investigate students' satisfaction in FC. For instance, a study conducted by Yoshida (2016) reported that the perceived usefulness of flipped classroom model could not only enhance students' understanding but improve the quality of classroom lessons. This could lead to students' satisfaction in FC.

Hypothesis 2: Perceived usefulness has positively influenced students' satisfaction.

\section{Perceived Ease of Use and Students' Satisfaction}

Perceived ease of use (EU) is a core construct of TAM and has been defined as the extent to which an individual believes that technology or a system is easy and effortless to use (Davis, 1989). Because of the partial 
literature on the relationship between EU and students' satisfaction in the FC setting, researchers refer to the existing studies of blended learning as FC is a subset of blended learning. Both blended learning and flipped classroom allow students to take online courses before the main class. In an FC context, EU is the extent to which leaner believes that it is easy to access online recorded videos and interact with learning materials before the class hours (Zhai et al., 2017). Most of the previous studies had focused on the effect of EU on students' satisfaction in a blended learning setting (Rahman, Hussein, \& Aluwi, 2015; Shah \& Attiq, 2016). These studies revealed that perceived ease of use had a strong influence on students' satisfaction. Limited empirical pertaining to the impact of EU on students' satisfaction in the flipped classroom is available. For example, Zhai et al. (2017) investigated the effect of selected factors on students' satisfaction in the flipped classroom context. The results showed that perceived ease of use played a critical role in students' satisfaction. As a result, the following hypothesis was drived.

Hypothesis 3: Perceived ease of use has positively influenced students' satisfaction.

\section{Perceived Value and Students' Satisfaction}

The concept of perceived value is being used in different fields and has been defined as the students' evaluation of the merits of a service or a product, and its ability to meet their expectations and desires, especially in comparison with its peers (Al-Debei \& Al-Lozi, 2014). Perceived value is a crucial indicator that requires special consideration when examining students' learning satisfaction (Gallarza \& Saura, 2006; Lin, Lee, \& Chen, 2005). Whenever implementing a new learning system such as flipped learning, students are expected to achieve their learning goals effectively. They may carefully consider how they spend versus how much they receive. A study was conducted to assess the factors affecting students' satisfaction in FC. The findings showed that perceived value played a significant role (Zhai et al., 2017). Another study revealed that perceived value was a strong determinant of students' satisfaction (Rahman et al., 2015). The following hypothesis was formulated:

Hypothesis 4: Perceived value has positively influenced students' satisfaction.

\section{METHODOLOGY}

Flipped classroom (FC) approach is used to teach undergraduate Information and Communication Technology (ICT) course during the second semester at one of the well-established universities in Nigeria. This study employed a quantitative approach to assess students' responses. There were a total population of 167 students from the Faculty of Education of the researched university. Based on Krejcie and Morgan (1971), a sample size of 115 was used. A questionnaire consists of two parts. The first part entails demographic information (gender, age, and program). The second part consists of 21 items to measure the four independent variables (instructor-generated video content, perceived ease of use, perceived usefulness, and perceived value) and a dependent variable (students' satisfaction). A five-point Likert scale was used to assess each item. The scale ranges from strongly disagree 1 to strongly agree 5 . The questionnaire was adopted from Zhai et al. (2017) and Draus et al. (2014) and modified to meet the study needs. Upon completing the course, the students were asked to complete the questionnaire anonymously. A total of 110 questionnaires were valid for analysis. Partial Least Square Structural Equation Model (PLS-SEM) was employed to run exploratory and confirmatory analyses to further confirm the suitability and reliability of the questionnaire. Factors that loaded below 0.7 were deleted as suggested by Hair $(2015,2017)$. Fifteen items across the four constructs were valid and used for the path analyses.

\section{ANALYSIS AND FINDINGS}

\section{Demographic Information}

Descriptive statistics show that males have the highest number of respondents $(n=61,55.5 \%)$ compared to the female who has less population $(\mathrm{n}=49,45.5 \%)$. Age was divided into four categories, and the majority of the respondents fell within the 22-24 range, representing a total of $36(32.7 \%)$, followed by the respondents whose age was fallen within 25-27 category $(n=26,23.6 \%)$, the least respondents were students with age of 19-21 category and 28 and above who have the same number $(n=24,21.8 \%)$. In terms of the program, most of the respondents were from the department of Chemistry Education $(n=30$, $26.1 \%)$, followed by Computer Science Education ( $n=24,21.8 \%)$. A less majority of the respondents were from department of Mathematics Education $(n=21,19.1 \%)$ and Biology Education $(n=19,17.3 \%)$. The least representation of the respondents was from Physics Education $(\mathrm{n}=16,14.5 \%)$

\section{Model Analysis}

A partial least square structural equation model (PLS-SEM) had been used for estimating (complex) path models with latent variables and their relationships (Sarstedt, Ringle, \& Hair, 2020). Therefore, PLSSEM was used to analyze the data in this research. Initially, the PLSSEM algorithm was run to assess the factor loadings of each item (see Figure 3). About seven items with low factor loadings were deleted as suggested by Hair, Hult, Ringle, and Sarstedt (2017). Secondly, Cronbach's Alpha, rho_A, composite reliability average variance extracted (AVE) were assessed as recommended by Hair et al. (2017), as shown in Table 1.

From Table 1, the Cronbach's Alpha values of the variables were ranged between 0.744 and 0.781 . Rho_A values array within the range of 0.748 and 0.875 . Composite reliability is more dependable than Cronbach's Alpha ranged between 0.852 and 0.898 . The above values demonstrate a good internal consistency. According to Hair et al. (2017), if the value of indicators is above 0.702 , the internal consistency of the measurement model is good and acceptable. The average variance extracted (AVE) values of 0.5 and above demonstrate a good internal consistency measurement model (Hair et al., 2017). The values of AVE fall between 0.659 and 0.815 meet the threshold of internal consistency. The overall reliability of the instrument is Cronbach's Alpha of 0.759 which is the average of all the variables' Alpha coefficient shows a good instrument for the measurement model.

\section{Discriminant Validity}

Discriminant validity is a type of construct validity that is recognized when measures of different constructs are demonstrated to be uncorrelated with each other (Rochefort, Baldwin, \& Chmielewski, 2018). Discriminant validity assumes that items should correlate higher among them than they correlate with other items from other constructs 


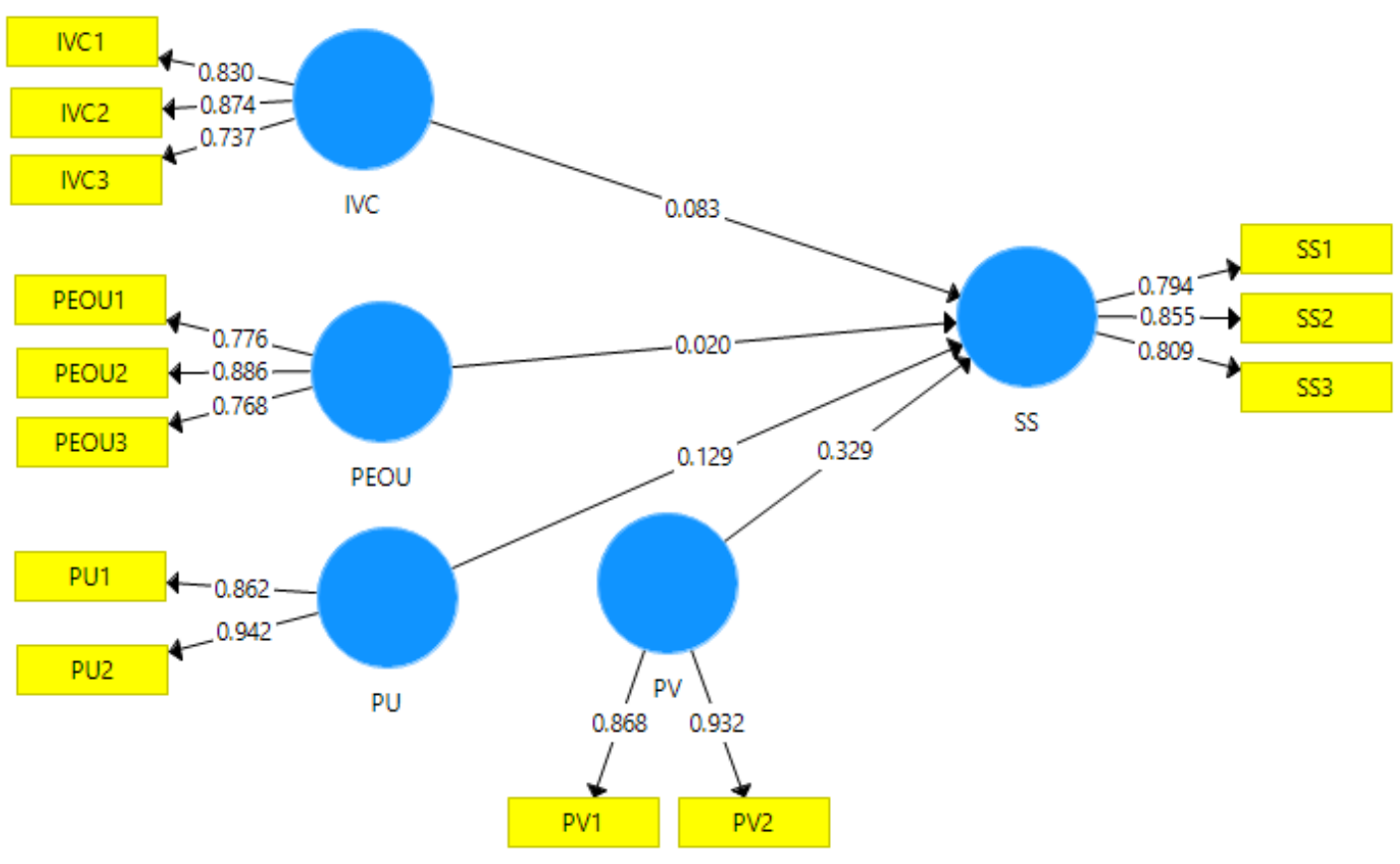

Figure 3. PLS algorithms for confirmatory factor analysis

Table 1. Reliability and Validity

\begin{tabular}{ccccc}
\hline Variable & Cronbach's Alpha & rho_A & Composite Reliability & $\begin{array}{c}\text { Average Variance } \\
\text { Extracted (AVE) }\end{array}$ \\
\hline IVC & 0.745 & 0.748 & 0.856 & 0.665 \\
\hline PEOU & 0.744 & 0.783 & 0.852 & 0.659 \\
\hline PU & 0.781 & 0.875 & 0.898 & 0.815 \\
\hline PV & 0.771 & 0.825 & 0.895 & 0.810 \\
\hline SS & 0.757 & 0.768 & 0.860 & 0.672 \\
\hline
\end{tabular}

Table 2. HTMT Results

\begin{tabular}{|c|c|c|c|c|c|}
\hline Variables & IVC & PEOU & $\mathrm{PU}$ & $\mathbf{P V}$ & SS \\
\hline IVC & 0 & & & & \\
\hline PEOU & 0.216 & 0 & & & \\
\hline $\mathrm{PU}$ & 0.263 & 0.326 & 0 & & \\
\hline PV & 0.368 & 0.369 & 0.206 & 0 & \\
\hline SS & 0.258 & 0.195 & 0.253 & 0.482 & 0 \\
\hline
\end{tabular}

Table 3. Collinearity Statistics

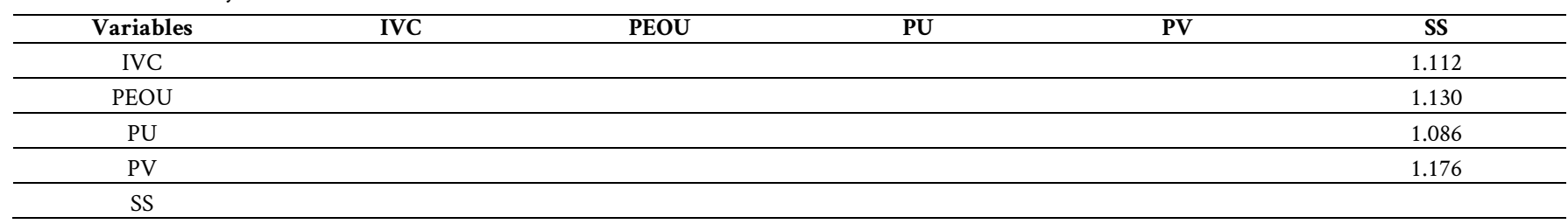

that are theoretically supposed not to correlate (Zait, Alexandru, \& Cuza, 2011, p. 1). Henseler, Hubona, and Ray (2016), and Hair et al. (2017) suggested that Heterotrait-Monotrait Ratio (HTMT) should be used to determine the discriminant validity. The results of HTMT are depicted in Table 2.

Results in Table 2 show that the discriminant validity is good and acceptable because all the corresponding loadings between two different variables were less than 0.85 as suggested by (Hair et al., 2017; Henseler et al., 2016). All the diagonal loadings are also zero. Therefore, no variables redundancy in the model.

\section{Collinearity}

Multicollinearity occurs when there is a high association or correlation between dependent variables or independent variables (Kim, 2019). High collinearity between variables affects the reliability and quality of the results (De Marco \& Nóbrega, 2018). To detect the collinearity of the data, Kock (2015), and Hair et al. (2017) proposed the use of a test of the variance inflation factors (VIF). Below are the results of the VIF analysis offered in Table 3.

Results in Table 3 show that all the VIF values are within the range of 1.086 and 1.176. They are below 3.3 and good for the model as 


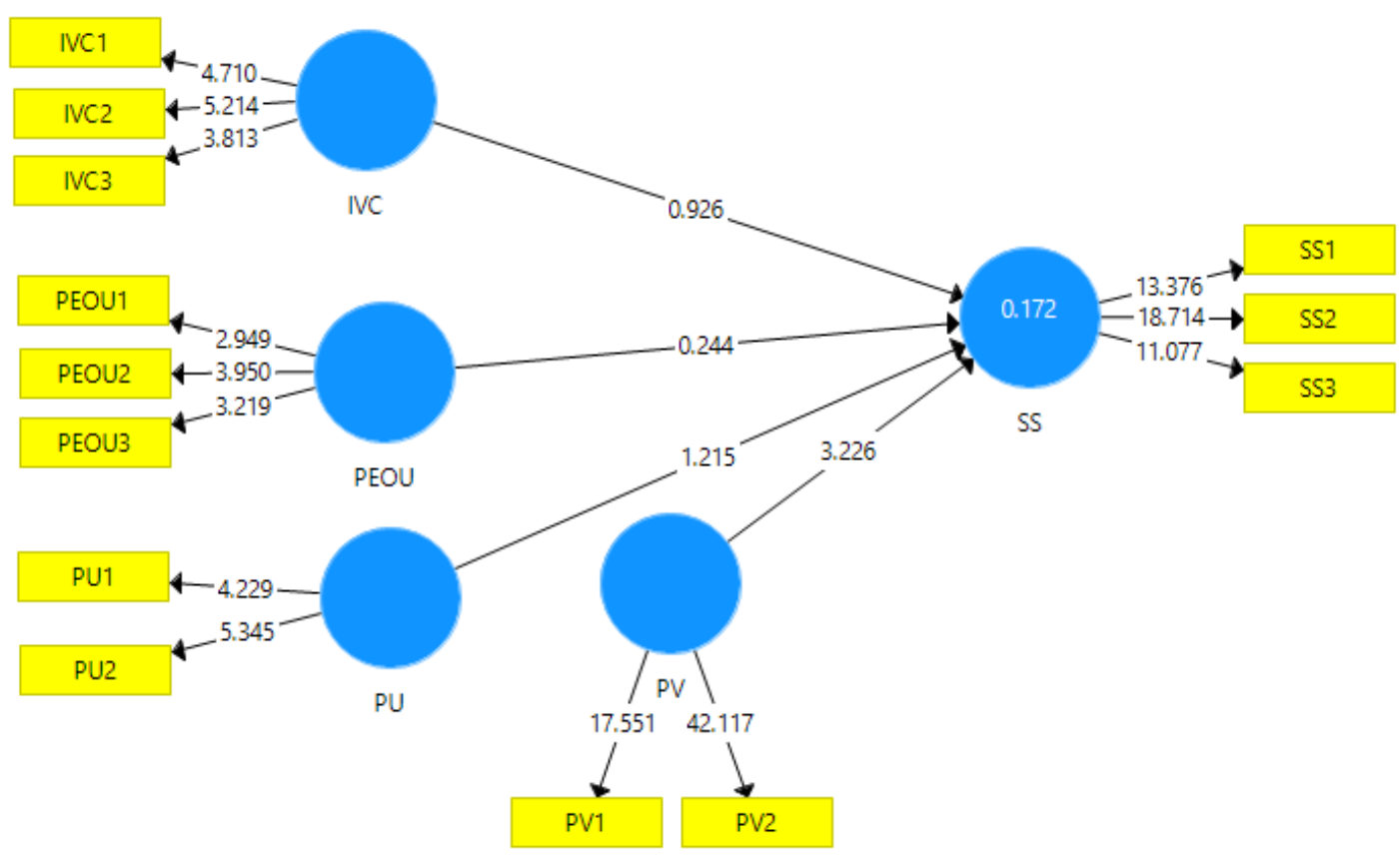

Figure 4. Bootstrapping results for path analysis

Table 4. Direct path analysis

\begin{tabular}{cccccc}
\hline Relationship & Beta-values & Sample Mean (M) & $\begin{array}{c}\text { Standard Deviation } \\
\text { (STDEV) }\end{array}$ & t-values & p-values \\
\hline IVC $>$ SS & 0.089 & 0.113 & 0.096 & 0.926 & 0.355 \\
\hline PEOU $>$ SS & 0.025 & 0.055 & 0.104 & 0.244 & 0.807 \\
\hline PU $>$ SS & 0.131 & 0.129 & 0.108 & 1.215 & 0.225 \\
\hline PV $>$ SS & 0.325 & 0.319 & 0.101 & 3.226 & 0.001 \\
\hline
\end{tabular}

recommended by Hair et al. (2017). The results indicated no disturbances in the data.

\section{Structural Model Analysis}

This study used structural model analysis to assess the relationship between the latent variables. Scholars recommended structural model analysis to analyse complex data in social science research (Hair et al., 2017; Henseler et al., 2016). For researchers to examine path relationship, the 5000 samples bootstrapping in PLS-SEM was run as suggested by Hair et al., (2017). The results of the path analysis are presented in Figure 4 and tabularized in Table 4.

Results of direct path analysis in Table 4 show that only one hypothesis has significantly influenced students' satisfaction. For instance, perceived value (PV) has significantly influenced students' satisfaction at $\mathrm{t}=3.226, \mathrm{p}<0.05$. However, three of the hypotheses were found to have no significant influence. For example, instructorgenerated video content (TC) has no significant influence on students' satisfaction at $\mathrm{t}=0.926, \mathrm{p}=0.355$, perceived ease of use (PEOU) found to have no significant effect on students' satisfaction at $\mathrm{t}=0.244, \mathrm{p}=0.807$. The results also reported perceived usefulness (PU) has no effect on students' satisfaction at $\mathrm{t}=1.215, \mathrm{p}=0.225$.

\section{DISCUSSION}

The traditional lecture-based method has been used in African countries. In this method, the teacher is the main actor in the classroom, and students are partially involved in the learning process. Under this circumstance, students might not attain maximum learning achievement and satisfaction. Therefore, it is critical to investigate the students' satisfaction to determine the efficacy of this FC model.

Results revealed that perceived value had a significant influence on students' satisfaction in the FC model. This finding is in line with that of Zhai et al. (2017), and Rahman, Hussein, and Aluwi (2015), who argued that perceived value played a vital role in students' satisfaction. The result further interprets that if the students believe their learning is interested, valuable, and enjoyable, their satisfaction increases. Students agreed that flipped classroom model meets their expectations and needs more than the traditional lecture-based method. It is also an indication that students learn more, achieve more, and satisfy more in a flipped classroom model.

The effect of instructor-generated video content has not been deeply explored in the field of flipped classroom model. Therefore, this study examines the influence of instructor-generated video content on students' satisfaction. The result shows that instructor-generated video content had no impact on students' satisfaction. It infers that video learning materials of flipped classroom model could be sourced from YouTube, Khan Academy, or Vimeo not necessarily made by the instructor (instructor-generated video content). Nevertheless, Draus et al. (2014), Yusuf and Prasad (2017), and Miller and Redman (2010) argued that instructor-generated video content had a significant influence on students' satisfaction. Perceived ease of use (PEOU) reflects how flipped learning model is easy to use and free from effort. This factor is critical in determining students' satisfaction in the flipped classroom, blended learning, and online learning (see Rahman et al., 2015; Shah \& Attiq, 2016; Zhai et al., 2017). However, for this study, the perceived ease of use was found to have no significant effect on students' 
satisfaction. It could be due to the students' experience in blended learning and online learning as they are used to having online materials such as video lectures to study before the class hour and having face-toface lectures inside the classroom. This factor shows no impact on students' satisfaction because most of the students are technology savvy and the learning model (flipped classroom) is fully technology oriented. The result further indicated that perceived usefulness had no significant influence on students' satisfaction. This result is supported by the research of Zhai et al. (2017) who found that the correlation between perceived usefulness and students' satisfaction was not significant.

\section{IMPLICATION OF THE STUDY}

The finding shows that only perceived value exhibits a certain level of positive implication towards students' satisfaction. Instructorgenerated video content, perceived usefulness, and perceived ease of use were found to have no significant impact on students' satisfaction. This study contributes to the existing literature because there are few related studies. Institutions or educators might consider these findings before the implementation of the flipped classroom model. Students should be made to know in detail the advantages and disadvantages of this learning model, and how it can improve their learning performance compared to the traditional lecture-based methods. While implementing the flipped classroom model, the instructor can adapt the instructional videos from a third party such as YouTube, Khan Academy, or Vimeo. There was no difference between self-recorded video (instructor-generated video content) and third-party video lectures.

\section{LIMITATIONS AND RECOMMENDATION FOR FUTURE STUDIES}

Due to the limited research sample, this study did not cover other populations as students from other institutions might have different opinions on satisfaction on flipped classroom model. Therefore, future researches need to be conducted to overcome the limitations. Future research should include larger sample size to extend the scope to generalize the findings to other sets of students with similar characteristics. More constructs and items could be incorporated to strengthen the quality of the research. Apart from that, mixed-method approach is recommended for data collection in future research.

\section{CONCLUSION}

The study explored the effect between factors (instructor-generated video content, perceived usefulness, perceived ease of use, and perceived value) and students' satisfaction. Within the context of this study, perceived value is the most significant element in determining students' satisfaction. However, instructor-generated video content, perceived usefulness, and perceived ease of use are irrelevant in determining students' satisfaction. This study concluded that students prefer flipped classroom model more than the traditional lecture-based method. Hence, the importance of the flipped classroom model as one of the newly effective teaching and learning pedagogy is observed. This study suggested that flipped classroom model can be an alternative to the traditional lecture-based method. Flipped classroom model can also improve the quality of learning by exposing students to different learning styles.

Author contributions: All authors were involved in concept, design, collection of data, interpretation, writing, and critically revising the article. All authors approve final version of the article.

Funding: The authors received no financial support for the research and/or authorship of this article.

Declaration of interest: Authors declare no competing interest.

Data availability: Data generated or analysed during this study are available from the authors on request.

\section{REFERENCES}

Ahuja, N. (2020). A study of awareness and effectiveness of flipped classroom approach among students in Mumbai City. UGC Care Journal, 40(51), 18-23.

Al-Debei, M. M., \& Al-Lozi, E. (2014). Explaining and predicting the adoption intention of mobile data services: A value-based approach. Computers in Human Behavior, 35, 326-338. https://doi.org/10.1016/j.chb.2014.03.011

Al-hawari, M. A., \& Mouakket, S. (2010). The influence of technology acceptance model (TAM) factors on students' e-satisfaction and eretention within the context of UAE e-learning. Education, Business and Society: Contemporary Middle Eastern Issues, 3(4), 299-314. https://doi.org/10.1108/17537981011089596

Ateş Çobanoğlu, A. (2018). Student teachers' satisfaction for blended learning via Edmodo learning management system. Behaviour and Information Technology, 37(2), 133-144. https://doi.org/10.1080/ 0144929X.2017.1417481

Bergmann, J., \& Sams, A. (2012). Flip your classroom reach every student in every class every day.

Bishop, J., \& Verleger, M. (2013). Testing the flipped classroom with model-eliciting activities and video lectures in a mid-level undergraduate engineering course. Proceedings - Frontiers in Education Conference, FIE, 161-163. https://doi.org/10.1109/ FIE.2013.6684807

Chen, W.-S., \& Tat Yao, A. Y. (2016). An empirical evaluation of critical factors influencing learner satisfaction in blended learning: A pilot study. Universal Journal of Educational Research, 4(7), 16671671. https://doi.org/10.13189/ujer.2016.040719

Cheng, X., Ka Ho Lee, K., Chang, E. Y., \& Yang, X. (2017). The “flipped classroom" approach: Stimulating positive learning attitudes and improving mastery of histology among medical students. Anatomical Sciences Education, 10(4), 317-327. https://doi.org/ 10.1002/ase. 1664

D’Aquila, J. M., Wang, D., \& Mattia, A. (2019). Are instructor generated YouTube videos effective in accounting classes? A study of student performance, engagement, motivation, and perception. Journal of Accounting Education, 47, 63-74. https://doi.org/10.1016/j.jaccedu.2019.02.002

De Marco, P., \& Nóbrega, C. C. (2018). Evaluating collinearity effects on species distribution models: An approach based on virtual species simulation. PloS one, 13(9), e0202403. https://doi.org/10.1371/journal.pone.0202403 
Draus, P., Curran, M., \& Trempus, M. (2014). The influence of instructor-generated video content on student satisfaction with and engagement in asynchronous online classes. Journal of Online Learning and Teaching, 10(2), 240.

Elian, S. A., \& Hamaidi, D. A. (2018). The effect of using flipped classroom strategy on the academic achievement of fourth grade students in Jordan. International Journal of Emerging Technologies in Learning, 13(2), 110-125. https://doi.org/10.3991/ijet.v13i02.7816

Gallarza, M. G., \& Saura, I. G. (2006). Value dimensions, perceived value, satisfaction and loyalty: An investigation of university students' travel behaviour. Tourism Management, 27(3), 437-452. https://doi.org/10.1016/j.tourman.2004.12.002

Hair, J. F., Hult, G. T. M., Ringle, C. M., \& Sarstedt, M. (2017). A primer on partial least squares structural equation modeling (2nd ed.). Sage. https://doi.org/10.15358/9783800653614

Hair, J. F., Hult, G. T. M., Ringle, C. M., Sarstedt, M. (2015). A primer on partial least squares structural equation modeling (PLS-SEM). SAGE Publications, Inc.

Hammouri, Q., \& Abu-Shanab, E. (2018). Exploring factors afecting users' satisfaction toward e-learning systems. International Journal of Information and Communication Technology Education, 14(1), 44-57. https://doi.org/10.4018/IJICTE.2018010104

Heijstra, T. M., \& Sigurðardóttir, M. S. (2018). The flipped classroom: Does viewing the recordings matter? Active Learning in Higher Education, 19(3), 211-223. https://doi.org/10.1177/ 1469787417723217

Henseler, J., Hubona, G., \& Ray, P. A. (2016). Using PLS path modeling in new technology research: Updated guidelines. Industrial Management \& Data Systems, 116(1), 2-20. https://doi.org/10.1108/ IMDS-09-2015-0382

Ibrahim, N. B., Ibrahim, N. S., Zukri, S. M., Syazwani, M., \& Mohd, M. (2019). Learners satisfaction of e-learning among public university students: A case study in Kota Bharu literature review. Journal of Mathematics and Computing Science, 5(1), 1-7.

Kim, J. H. (2019). Multicollinearity and misleading statistical results. Korean Journal of Anesthesiology, 72(6), 558. https://doi.org/10.4097 /kja.19087

Kim, M. K., Kim, S. M., Khera, O., \& Getman, J. (2014). The experience of three flipped classrooms in an urban university: An exploration of design principles. Internet and Higher Education, 22, 37-50. https://doi.org/10.1016/j.iheduc.2014.04.003

Kock, N. (2015). Common method bias in PLS-SEM: A full collinearity assessment approach. International Journal of e-Collaboration (IJeC), 11(4), 1-10. https://doi.org/10.4018/ijec.2015100101

Krejcie, R. V., \& Morgan, D. W. (1970). Determining sample size for research activities. Educational and psychological measurement, 30(3), 607-610. https://doi.org/10.1177/001316447003000308

Lai, C.-L., \& Hwang, G. J. (2016). A self-regulated flipped classroom approach to improving students' learning performance in a mathematics course. Computers and Education, 100, 126-140. https://doi.org/10.1016/j.compedu.2016.05.006

Lai, G. H. C. (2015). Seamless flipped learning: a mobile technologyenhanced flipped classroom with effective learning strategies. Journal of Computers in Education, 2(4), 449-473. https://doi.org/10.1007/s40692-015-0043-0
Lin, H. C., Lee, H.-M., \& Chen, Y.-H. (2005). Personalized e-learning system using item response theory. Computers and Education, 44(3), 237-255. https://doi.org/10.1016/j.compedu.2004.01.006

Lizhu, Z., Debin, X., Ping, W., \& Deyan, K. (2018). Teacher's organizational form and role of flipped classroom. 4th International Conference on Social Science and Higher Education, 181(Icsshe), 512 514.

Lo, C. K., Lie, C. W., \& Hew, K. F. (2018). Applying "First Principles of Instruction" as a design theory of the flipped classroom: Findings from a collective study of four secondary school subjects. Computers and Education. https://doi.org/10.1016/j.compedu.2017.12.003

Manoj, K., Renumol, V., \& Murthy, S. (2019). Flipped classroom strategy to help underachievers in Java programming, 44-49. https://doi.org/10.1109/latice.2018.000-7

Miller, S. T., \& Redman, S. L. (2010). Improving instructor presence in an online introductory astronomy course through video demonstrations. Astronomy Education Review, 9(1), 1-8. https://doi.org/10.3847/aer2009072

Missildine, K., Fountain, R., Summers, L., \& Gosselin, K. (2013). Flipping the classroom to improve student performance and satisfaction. Journal of Nursing Education, 52(10), 597-599. https://doi.org/10.3928/01484834-20130919-03

Mtebe, J. S., \& Raphael, C. (2018). Key factors in learners' satisfaction with the e-learning system at the University of Dar es Salaam, Tanzania. Australasian Journal of Educational Technology, 34(4), 107122. https://doi.org/10.14742/ajet.2993

Murillo-Zamorano, L. R., López Sánchez, J. Á., \& Godoy-Caballero, A. L. (2019). How the flipped classroom affects knowledge, skills, and engagement in higher education: Effects on students' satisfaction. Computers and Education, 141(October 2018), 1-18. https://doi.org/10.1016/j.compedu.2019.103608

Nortvig, A. M., Petersen, A. K., \& Balle, S. H. (2018). A literature review of the factors influencing e-learning and blended learning in relation to learning outcome, student satisfaction and engagement. Electronic Journal of E-Learning, 16(1), 45-55.

O'Flaherty, J., \& Phillips, C. (2015). The use of flipped classrooms in higher education: A scoping review. Internet and Higher Education, 25(May), 85-95. https://doi.org/10.1016/j.iheduc.2015.02.002

Ong, C. S., Day, M. Y., \& Hsu, W. L. (2009). The measurement of user satisfaction with question answering systems. Information $\mathcal{E}$ Management, 46(7), 397-403. https://doi.org/10.1016/j.im.2009.07. 004

Onojah, A. O., Olumorin, C. O., Adegbija, M. V., \& Babalola, T. O. (2019). Perception of undergraduate students on the utilisation of flipped classroom for learning in South-West Nigeria. Malaysian Journal of Distance Education, 21(1), 95-112. https://doi.org/10.21315/mjde2019.21.1.6

Ozdamli, F., \& Asiksoy, G. (2016). Flipped classroom approach. World Journal on Educational Technology, 8(2), 98-105. https://doi.org/10.18844/wjet.v8i2.640

Panopto. (2015). The practical guide to flipping your classroom. 
Portz, J. D., Bayliss, E. A., Bull, S., Boxer, R. S., Bekelman, D. B., Gleason, K., \& Czaja, S. (2019). Using the technology acceptance model to explore user experience, intent to use, and use behavior of a patient portal among older adults with multiple chronic conditions: Descriptive qualitative study. Journal of Medical Internet Research, 21(4), e11604. https://doi.org/10.2196/11604

Rahman, N. A. A., Hussein, N., \& Aluwi, A. H. (2015). Satisfaction on blended learning in a public higher education institution: What factors matter? Procedia - Social and Behavioral Sciences, 211(September), 768-775. https://doi.org/10.1016/j.sbspro.2015. 11.107

Revere, L., \& Kovach, J. (2011). Online technologies for engaged learning: A meaningful synthesis for educators. Quarterly Review of Distance Education, 12(2), 113-124.

Robinson, S., \& Stubberud, H. A. (2012). Student preferences for educational materials: Old meets new. Academy of Educational Leadership Journal, 5(2), 127.

Rochefort, C., Baldwin, A. S., \& Chmielewski, M. (2018). Experiential avoidance: An examination of the construct validity of the AAQ-II and MEAQ. Behavior Therapy, 49(3), 435-449. https://doi.org/10.1016/j.beth.2017.08.008

Sams, A., Bergmann, J., Daniels, K., Bennett, B., Marshall, H., \& Artstrom, K. (2014). Flipped Learning Network (FLN) The four pillars of F-L-I-P. The Flipped Learning Network, 501(c).

Sarstedt, M., Ringle, C. M., \& Hair, J. F. (2020). Handbook of Market Research. In C. Homburg, Klarmann, M., \& A. E. Vomberg (Eds.), Handbook of Market Research. Springer. https://doi.org/10.1007/978-3-319-05542-8

Shah, H. J., \& Attiq, S. (2016). Impact of technology quality, perceived ease of use and perceived usefulness in the formation of consumer's satisfaction in the context of e-learning hassan. Abasyn Journal of Social Sciences, 9(1), 124-140.

Tarafdar, M., Tu, Q., \& Ragu-Nathan, T. S. (2010). Impact of technostress on end-user satisfaction and performance. Journal of management information systems, 27(3), 303-334. https://doi.org/10.2753/MIS0742-1222270311

Toto, R., \& Nguyen, H. (2009). Flipping the work design in an industrial engineering course. Proceedings - Frontiers in Education Conference, FIE, 1-4. https://doi.org/10.1109/FIE.2009.5350529
Wen, A. S., Zaid, N. M., \& Harun, J. (2017). Enhancing students ICT problem solving skills using flipped classroom model. 2016 IEEE 8th International Conference on Engineering Education: Enhancing Engineering Education Through Academia-Industry Collaboration, ICEED 2016, 187-192. https://doi.org/10.1109/ICEED.2016. 7856069

Wu, W. C. V., Hsieh, J. S. C., \& Yang, J. C. (2017). Creating an online learning community in a flipped classroom to enhance efl learners' oral proficiency. Educational Technology and Society, 20(2), 142-157.

Yilmaz, R. (2017). Exploring the role of e-learning readiness on student satisfaction and motivation in flipped classroom. Computers in Human Behavior, 70, 251-260. https://doi.org/10.1016/j.chb.2016. 12.085

Yoshida, H. (2016). Perceived usefulness of "flipped learning" on instructional design for elementary and secondary education: With focus on pre-service teacher education. International Journal of Information and Education Technology, 6(6), 430-434. https://doi.org/10.7763/ijiet.2016.v6.727

Yusuf, J., \& Prasad, D. (2017). Using instructor - generated short videos in an undergraduate accounting information system course. International Journal of Instructional Technology and Distance Learning, 14(11), 43-52.

Zainuddin, Z., Haruna, H., Li, X., Zhang, Y., \& Chu, S. K. W. (2019). A systematic review of flipped classroom empirical evidence from different fields: what are the gaps and future trends? On the Horizon, 27(2), 72-86. https://doi.org/10.1108/OTH-09-2018-0027

Zait, A., Alexandru, U., \& Cuza, I. (2011). Methods for testing discriminant validity. Management and Marketing Journal, IX(2), 217-224.

Zhai, X., Gu, J., Liu, H., Liang, J. C., \& Tsai, C. C. (2017). An experiential learning perspective on students' satisfaction model in a flipped classroom context. Educational Technology and Society, 20(1), 198210.

Zou, D. (2020). Gamified flipped EFL classroom for primary education: student and teacher perceptions. Journal of Computers in Education, 7(2), 213-228. https://doi.org/10.1007/s40692-020-00153-w 